INFLAMMATORY BOWEL DISEASE

\title{
Increased epithelial uptake of protein antigens in the ileum of Crohn's disease mediated by tumour necrosis factor $\alpha$
}

\author{
J D Söderholm, C Streutker, P-C Yang, C Paterson, P K Singh, D M McKay, P M Sherman, \\ K Croitoru, M H Perdue
}

See end of article for authors' affiliations

Correspondence to: Dr J D Söderholm, Department of Surgery, University Hospital, SE58185 Linköping, Sweden; johda@ibk.liu.se

Revised version received 3 May 2004

Accepted for publication 4 May 2004
Background and aims: The exact nature of the epithelial barrier defect in Crohn's disease remains to be elucidated. Previously we showed increased permeability to proteins in ileal Crohn's disease. Our aims were to study if this barrier defect (a) involves endocytotic uptake of antigens and (b) is related to low grade inflammation not detectable by histology.

Methods: Macroscopically normal segments of distal ileum of Crohn's disease patients $(n=10)$ were subgrouped into non-inflamed (histologically unaffected) and slightly inflamed tissues and studied in Ussing chambers, with normal ileal specimens from colon cancer patients $(n=9)$ as controls. Endocytotic uptake into enterocytes of the protein antigen horseradish peroxidase was assessed by measuring the area of horseradish peroxidase containing endosomes in electron photomicrographs. Mucosal tumour necrosis factor $\alpha(T N F-\alpha)$ mRNA was quantified using real time polymerase chain reaction. For comparison, the effects of low doses of TNF- $\alpha$ on endosomal uptake of horseradish peroxidase were studied in cultured T84 cells grown on filter supports.

Results: The area of horseradish peroxidase containing endosomes was increased $(p<0.001)$ in enterocytes of non-inflamed ileum of Crohn's disease (2.8 $(0.7) \mu \mathrm{m}^{2} / 300 \mu \mathrm{m}^{2}$ ) compared with control ileum (0.6 (0.06)). In non-inflamed mucosa, a significant association between endosomal uptake and mucosal expression of TNF- $\alpha$ mRNA $(p=0.03)$ was found. Low concentrations of TNF- $\alpha(0.25-1.0 \mathrm{ng} / \mathrm{ml})$ enhanced the endosomal uptake of horseradish peroxidase in polarised T84 cells, without affecting transepithelial electrical resistance.

Conclusions: Our findings suggest increased endosomal uptake of antigens in ileal Crohn's disease that may be mediated by TNF- $\alpha$. These data highlight the transcellular route of antigen uptake in barrier dysfunction and implicate the interaction between epithelial cells and the innate immune system in the development of mucosal inflammation.
$\mathrm{T}$ he last decade of research has given us insights into the critical role of the bacterial flora and the importance of dysregulation of the mucosal immune system in intestinal inflammation. The intestinal epithelial barrier is the interface between these two environments, and sufficient disruption of the barrier can initiate and perpetuate inflammation. ${ }^{1-3}$

Increased intestinal permeability to medium sized molecules, reflecting paracellular permeability, is a characteristic of intestinal inflammation. In patients with Crohn's disease (CD), increased gut permeability can predict relapse and may precede histological inflammation. ${ }^{45}$ Several studies have demonstrated a subgroup of first degree relatives with a disrupted intestinal barrier, ${ }^{6-10}$ and a case report has shown development of $\mathrm{CD}$ in a relative eight years after a finding of increased intestinal permeability. ${ }^{11}$ Therefore, increased intestinal permeability has been suggested as a factor of pathogenic importance in CD. On the other hand, increased permeability in CD is related to disease activity, ${ }^{45}$ and recently Suenaert and colleagues ${ }^{12}$ reported that treatment with anti-tumour necrosis factor $\alpha$ (TNF- $\alpha$ ) antibody largely restores the gut barrier in $\mathrm{CD}$. This could imply that increased permeability in CD is secondary to the inflammatory process. Moreover, Yacyshyn and colleagues ${ }^{13}$ found coexistence of increased permeability and increased expression of activation markers on peripheral blood lymphocytes in CD relatives, suggesting that the disturbed permeability in relatives of $C D$ is also associated with an activated immune system. The recent findings that $50 \%$ of healthy CD relatives show signs of subclinical intestinal inflammation ${ }^{14}$ also support this concept. This underlines the need for studies of immune regulation of the mucosal barrier in the pathophysiology of CD.

Data from animal models of intestinal inflammation have revealed that conditions with an increased intestinal permeability to medium sized molecules in vivo show a combination of increased tight junction permeability and enhanced flux of proteins (mainly transcellular uptake) when studied in Ussing chambers in vitro. ${ }^{15}{ }^{16}$ A combination of enhanced permeability to proteins and tight junction dysfunction was also found in ileal CD mucosa studied in vitro, ${ }^{17}{ }^{18}$ as well as in ulcerative colitis. ${ }^{1920}$ While regulation of paracellular permeability has received much attention in recent years, ${ }^{21-25}$ little is known about transcellular uptake of antigens in human inflammatory bowel disease.

TNF- $\alpha$ is one of the most important proinflammatory mediators in CD, and treatment with anti-TNF- $\alpha$ has become a cornerstone in CD treatment. Moreover, an important role of TNF- $\alpha$ in regulating intestinal barrier function (transcellular and paracellular route) has been demonstrated by coculture of intestinal cell lines with human mononuclear cells from patients with active $\mathrm{CD},{ }^{26}$ as well as from patients with human immunodeficiency virus enteropathy, ${ }^{27}$ cow's

\footnotetext{
Abbreviations: CD, Crohn's disease; Isc, short circuit current; HRP, horseradish peroxidase; RT-PCR, reverse transcripion-polymerase chain reaction; $P D$, potential difference; TER, transepithelial electrical resistance; TNF- $\alpha$, tumour necrosis factor $\alpha$; GAPDH, glyceraldehyde-3phosphate dehydrogenase
} 
milk allergy, ${ }^{28}$ and monocytes activated by bacterial superantigen. ${ }^{29}$ In a previous study, ${ }^{18}$ we showed increased permeability to ovalbumin in non-inflamed ileum of $\mathrm{CD}$, possibly via the transcellular route. From this study two important questions have emerged: Does the barrier defect in ileal CD involve endocytotic uptake of antigens as a first step of transcytosis? And, if so, is this related to low grade inflammation (not detectable by histology) and TNF- $\alpha$ production?

The present study shows that increased endosomal uptake of the protein antigen horseradish peroxidase (HRP) into enterocytes was correlated with expression of TNF- $\alpha$ mRNA in histologically unaffected ileal mucosa of CD. Moreover, low concentrations of TNF- $\alpha$ induced increased epithelial endocytosis of HRP in polarised T84 cells. Our findings suggest that mucosal barrier dysfunction in the pathogenesis of CD includes the transcellular route and may be secondary to release of TNF- $\alpha$.

\section{METHODS}

\section{Experiments in human tissue}

Patients and ethics

The study comprised 10 patients operated on for CD (table 1), with nine patients undergoing surgery for colonic cancer as controls. CD patients (seven women, three men), had a median age of 32 (range 21-59) years and underwent elective surgery for ileal $(n=8)$ or ileocolonic $(n=2)$ CD at McMaster University Medical Centre. Disease duration prior to the present surgery was 4 (range 1-15) years; eight were primary resections and two re-resections. Six patients were on maintenance treatment with azathioprine or 6-mercaptopurine and four were receiving corticosteroids with or without mesalasine. Indications for surgery were obstructive symptoms in five cases, previous intra-abdominal abscesses in three cases, and enterocolonic fistulas in two patients. Ileocaecal resection was performed in eight patients whereas combined ileal and more extended colonic resection was done in the remaining two. Nine patients (six men) operated on for right hemicolectomy $(\mathrm{n}=5)$ or subtotal colectomy $(n=4)$ for colon cancer, aged 55 (range 45-81) years, served as controls. The colon cancer patients had no evidence of generalised disease. None had received preoperative chemotherapy or radiotherapy.

The study was approved by the Ethics Committee, Faculty of Health Sciences, McMaster University, and was conducted according to the Declaration of Helsinki.

\section{Ussing chamber experiments}

Surgical specimens of distal ileum from patients with CD $(\mathrm{n}=10)$ were studied, with normal ileal mucosal specimens from colon cancer patients $(n=9)$ as controls. Immediately after removal of the vascular supply to the distal ileum, segments were put into cold oxygenated Krebs' buffer and then macroscopically reviewed by a pathologist (CS). Macroscopically non-involved segments were stripped of muscle layers and 2-4 adjacent pieces from each patient were mounted in modified Ussing chambers (W-P Instruments, Narco Scientific, Mississauga, Ontario, Canada). The chamber opening exposed $0.6 \mathrm{~cm}^{2}$ of tissue surface area to $8 \mathrm{ml}$ of circulating oxygenated Krebs buffer at $37^{\circ} \mathrm{C}$. The buffer contained (in $\mathrm{mM}$ ) $115 \mathrm{NaCl}, 1.25 \mathrm{CaCl}_{2}, 1.2$ $\mathrm{MgCl}_{2}, 2.0 \mathrm{KH}_{2} \mathrm{PO}_{4}$, and $25 \mathrm{NaHCO}_{3}, \mathrm{pH} 7.35 \pm 0.02$. In addition, the serosal buffer contained $10 \mathrm{mM}$ glucose as an energy source, osmotically balanced by $10 \mathrm{mM}$ mannitol in the mucosal buffer. Agar salt bridges were used to monitor the potential difference (PD) across the tissue and to inject the required short circuit current $\left(\mathrm{I}_{\mathrm{sc}}\right)$ to maintain a zero potential difference, as registered via an automated voltage clamp (W-P Instruments). $\mathrm{I}_{\mathrm{sc}}\left(\mu \mathrm{A} / \mathrm{cm}^{2}\right)$ was recorded continuously by a computer and tissue conductance was calculated according to Ohm's law and expressed as $\mathrm{mS} / \mathrm{cm}^{2}$. Baseline values for $\mathrm{I}_{\mathrm{sc}}$ (active ion secretion) and conductance (passive ion permeability) were assessed at equilibrium, 15 minutes after mounting the tissues. At this time point, HRP was added to the luminal chamber. In the five minute experiments, tissues were then fixed in glutaraldehyde without further electrical measurements. In the 20 minute experiments, $\mathrm{I}_{\mathrm{sc}}$ was studied at baseline, following transmural nerve stimulation, and after addition of glucose $(10 \mathrm{mM})$ to the luminal side. A PD of $6 \mathrm{mV}$ with glucose in the luminal chamber was previously determined as a parameter of viability. ${ }^{18}{ }^{30}$ Therefore, a prerequisite for inclusion in the present study was a rise in PD to no less than $6 \mathrm{mV}$ after luminal addition of glucose in the 20 minute experiments.

\section{Epithelial uptake of HRP}

Endocytotic uptake into epithelial cells was assessed in ileal segments after five minutes and 20 minutes of luminal exposure to HRP. At these time points, tissues were removed from the chambers and immediately fixed in $2.5 \%$ glutaraldehyde in 0.1 M sodium cacodylate buffer ( $\mathrm{pH} 7.4$ ) for two hours at $22^{\circ} \mathrm{C}$, rinsed for 18 hours $\left(4^{\circ} \mathrm{C}\right)$ with $0.05 \mathrm{M}$ Tris buffer ( $\mathrm{pH}$ 7.6), and washed three times, five minutes each time. Methods for HRP product identification were modified from Graham and Karnovsky. ${ }^{31}{ }^{32}$ In brief, peroxidase activity was demonstrated by incubating tissues for 15 minutes in $0.5 \mathrm{mg} / \mathrm{ml}$ diaminobenzidine in $0.05 \mathrm{M}$ Tris buffer $(\mathrm{pH} 7.6$, $22^{\circ} \mathrm{C}$ ), followed by 15 minutes of incubation in the same buffer containing $0.01 \% \mathrm{H}_{2} \mathrm{O}_{2}$. Subsequently, tissues were processed for transmission electron microscopy. Quantitative analysis of HRP uptake in intracellular endosomes and

Table 1 Characteristics of the patients and histological assessment of ileal specimens in the 10 patients with Crohn's disease included in the study

\begin{tabular}{|c|c|c|c|c|c|c|c|c|c|c|c|}
\hline $\begin{array}{l}\text { Patient } \\
\text { No }\end{array}$ & $\begin{array}{l}\text { Age } \\
\text { (y) }\end{array}$ & Sex & Disease location & Medication & $\begin{array}{l}\text { Indication } \\
\text { for surgery }\end{array}$ & $\begin{array}{l}\text { Neutro } \\
\text { Ip }\end{array}$ & $\begin{array}{l}\text { Neutro } \\
\text { epith }\end{array}$ & $\begin{array}{l}\text { Mono } \\
\text { Ip }\end{array}$ & Atrophy & Oedema & $\begin{array}{l}\text { LM } \\
\text { score }\end{array}$ \\
\hline 1 & 26 & $F$ & Ileocaecal & Steroids & Obstruction & 2 & 1 & 1 & 1 & 0 & 5 \\
\hline 2 & 35 & $M$ & lleum+colon & Azathioprine & Abscess & 2 & 0 & 1 & 0 & 0 & 3 \\
\hline 3 & 59 & $M$ & Ileum+colon & Azathioprine & Fistula & 0 & 0 & 0 & 0 & 0 & 0 \\
\hline 4 & 34 & $\mathrm{~F}$ & Ileocaecal & Azathioprine & Obstruction & 1 & 0 & 1 & 0 & 0 & 2 \\
\hline 5 & 34 & $\mathrm{~F}$ & lleocaecal & Steroids & Obstruction & 2 & 1 & 1 & 1 & 1 & 6 \\
\hline 6 & 21 & $\mathrm{~F}$ & lleocaecal & Steroids & Abscess & 2 & 1 & 0 & 0 & 0 & 3 \\
\hline 7 & 24 & $\mathrm{~F}$ & Ileocaecal & Steroids & Fistula & 1 & 0 & 0 & 0 & 0 & 1 \\
\hline 8 & 33 & $\mathrm{~F}$ & Ileocaecal & Azathioprine & Obstruction & 0 & 0 & 1 & 0 & 0 & 1 \\
\hline 9 & 31 & $\mathrm{~F}$ & Ileocaecal & Azathioprine & Abscess & 1 & 0 & 1 & 0 & 0 & 2 \\
\hline 10 & 31 & $M$ & lleocaecal & Azathioprine & Obstruction & 1 & 0 & 1 & 0 & 0 & 2 \\
\hline
\end{tabular}

Neutro lp, semiquantification of neutrophils in the lamina propria; Mono lp, semiquantification of mononuclear cells in the lamina propria; LM score, light microscopy score. 
paracellular HRP transport were performed on coded high magnification photomicrographs, 12 per patient. At the five minute time point, photomicrographs from six control patients, six non-inflamed CD, and four inflamed CD were assessed. At 20 minutes, photomicrographs from three controls and five CD patients (two non-inflamed, three slightly inflamed) were studied. The total area of HRP containing endosomes within enterocytes from the midvillus region was determined in an area of $300 \mu \mathrm{m}^{2}$ in the apical region of the cells, using a computerised image analysis system (Kontron Mop Videoplan, Kontron, Eching, Germany). ${ }^{33}$ Preliminary studies determined that endogenous peroxidase was not evident in gut epithelial cells of either controls or CD patients.

\section{Quantification of tissue TNF- $\alpha$ mRNA using real time PCR}

Samples for polymerase chain reaction (PCR) were snap frozen and stored at $-70^{\circ} \mathrm{C}$ until subsequent analyses. For RNA extraction, the tissue was pulverised in liquid $\mathrm{N}_{2}$ and RNA was extracted using Trizol (Invitrogen, Carlsbad, California, USA) according to the product protocol. RNA concentration was determined by spectrophotometry at OD $260 \mathrm{~nm}$ and the quality of RNA by the presence of intact 18S and 28S rRNA after electrophoresis on an ethidium bromide stained $1 \%$ agarose gel. After RNA isolation, $10 \mu \mathrm{g}$ of each sample were treated with DNase I to remove genomic DNA using the DNA free kit (Ambion, Austin, Texas, USA). Purified samples were then re-quantified and $1 \mu \mathrm{g}$ utilised for reverse transcription with the RETROscript kit (Ambion). After the completed reaction each sample was diluted to $200 \mu \mathrm{l}$ with nuclease free water (Ambion) and stored at $-20^{\circ} \mathrm{C}$ until use. For real time PCR, each well contained human glyceraldehyde-3-phosphate dehydrogenase (GAPDH) forward and reverse primers $(10 \mu \mathrm{m}, 1.25 \mu \mathrm{l} /$ reaction; Applied Biosystems, Foster City, California, USA), GAPDH probe (VIC reporter, $20 \mu \mathrm{m}, 1.25 \mu \mathrm{l} /$ reaction), Taqman Universal PCR master mix (12.5 $\mu \mathrm{l}$; Applied Biosystems), TNF- $\alpha$ primers and probe (human TNF- $\alpha$ Pre-developed Assay Reagent, FAM reporter, catalogue No 4327055; Applied Biosystems, ) $5 \mu \mathrm{l}$ of nuclease free water, and $5 \mu \mathrm{l}$ of sample cDNA. For each run, a non-transcribed sample of RNA reaction mix as well as a reverse transcription (RT) reaction mix with no cDNA present was utilised as a control. All samples were run in triplicate. PCR was done in the ABI PRISM 6700 Sequence Detection system. Gene expression was quantified relative to expression of GAPDH. TNF- $\alpha$ mRNA expression in control patients was averaged to obtain baseline expression, and expression in CD tissues was then divided by control expression and the results presented as percentage of control.

\section{Histology}

Tissue was taken adjacent to that studied in the Ussing chamber, fixed in $4 \%$ formaldehyde, embedded in paraffin, sectioned, and stained with haematoxylin-eosin. Cases were reviewed by a pathologist (CS) who was blinded with respect to the type of experiment and underlying diagnosis. Each case was assessed for degree of polymorphonuclear leucocyte infiltration in the lamina propria and epithelium, respectively, lymphocyte infiltration (chronic inflammation), mucosal atrophy, and mucosal oedema. This was performed utilising semiquantitative scales: 0, normal appearance; 1, mild changes; 2 , moderate changes; and 3 , severe changes. A histology score (0-15) was created from the sum of these variables in each specimen (table 1). Control patients had normal appearing ileal mucosa, with histology scores of 0-1. CD cases within the non-inflamed group had a normal
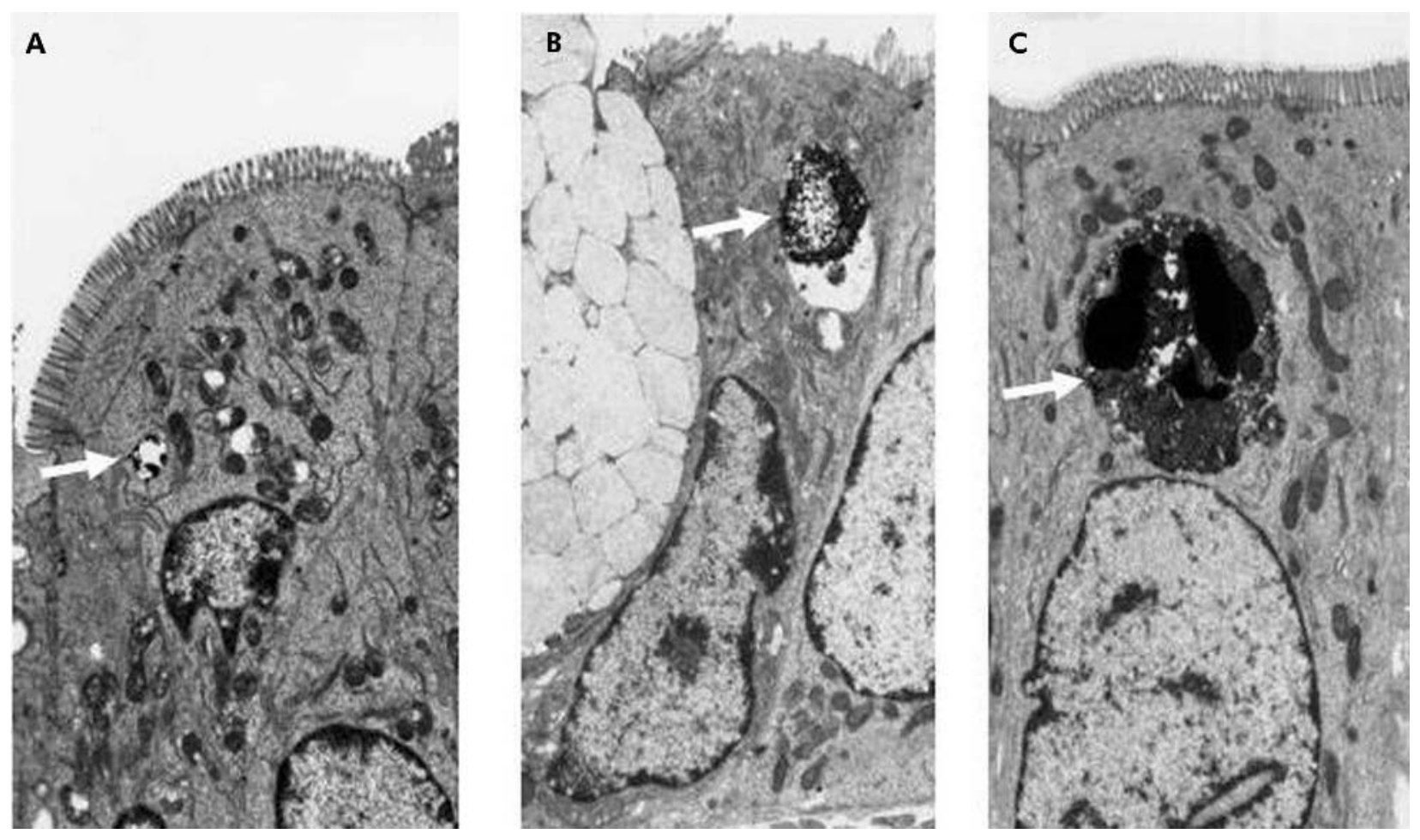

Figure 1 Increased endosomal uptake of horseradish peroxidase (HRP) in Crohn's disease (CD). Representative transmission electron photomicrographs of mid-villus ileal epithelium from a control patient $(A)$ and the non-inflamed ileum of patients with $C D(B, C)$, fixed five minutes after addition of HRP to the luminal buffer in Ussing chambers. HRP containing endosomes are indicated by arrows. Note the difference in endosome area between CD and control patients (see fig 2). Original magnification $\times 5000$. 
macroscopic and microscopic appearance, and had scores of 0-2 when scrutinised. In the slightly inflamed group, histology score was 3-6 but all specimens had an intact mucosa (that is, no ulcers or erosions were observed).

\section{Experiments using the T84 cell line} Cell culture

T84 epithelial cells were seeded $\left(10^{6}\right.$ cells $)$ on tissue culture treated Transwell filter supports $\left(0.4 \mu \mathrm{m}\right.$ pore size, $1.2 \mathrm{~cm}^{2}$ surface area; Costar, Cambridge, Massachusetts, USA). Culture medium consisted of a 1:1 mixture of DMEM and Ham's F-12 nutrient mixture (Gibco, Grand Island, New York, USA) supplemented with $10 \%$ (vol/vol) heat inactivated fetal bovine serum (Cansera International, Rexdale, Ontario, Canada), 1.5\% HEPES (Gibco), and 2\% penicillin-streptomycin (Gibco). Cells were grown at $37^{\circ} \mathrm{C}$ in $5 \% \mathrm{CO}_{2}$ for seven days to attain polarised epithelial monolayers with a transepithelial resistance (TER) of $>1000 \Omega \mathrm{cm}^{2}$. Monolayer resistance was monitored throughout the experimental period using a Millicell-ERS system (Millipore, Bedford, Massachusetts, USA). TER serves as a measure of the ability of T84 cells to restrict passive movement of ions.

\section{Treatment of monolayers with TNF- $\alpha$}

Confluent monolayers were cultured for 48 hours before the flux experiments with $0-10.0 \mathrm{ng} / \mathrm{ml}$ of recombinant human TNF- $\alpha$ (R\&D Systems, Minneapolis, Minnesota, USA) added to the basal compartment (volume $1.5 \mathrm{ml}$ ) of the Transwell unit. TNF- $\alpha$ doses were chosen based on previous studies showing only minor effects on TER in these concentrations. ${ }^{35-37}$

\section{Transepithelial transport of HRP}

HRP (molecular weight 44 000, type VI-A; Sigma, St Louis, Missouri, USA) was added to the apical side of the monolayers at a concentration of $10^{-5} \mathrm{M}$, and monolayers were incubated for two hours at $37^{\circ} \mathrm{C}$. Media samples were obtained from the basal compartments and assayed for HRP as described above.

\section{Electron microscopy}

To determine the route and magnitude of transepithelial transport of HRP, T84 monolayers exposed to HRP were processed for transmission electron microscopy. Briefly, 120 minutes after HRP addition, T84 monolayers were fixed with $2.5 \%$ glutaraldehyde in $0.1 \mathrm{M}$ sodium cacodylate buffer $(\mathrm{pH}$ 7.4) and further processed as described above. The 120 minute time period was chosen to enable simultaneous measurement of HRP containing endosomes, HPR fluxes, and the presence or absence of HRP in the tight junctions. An observer unaware of the treatment groups (P-CY) analysed random photomicrographs. For each experimental group, intracellular HRP was quantified by determining the total endosomal HRP area in $300 \mu \mathrm{m}^{2}$ windows (12 windows/ group, three separate experiments). Tight junctions and paracellular regions were also reviewed in a blinded fashion for the presence of HRP.

\section{Statistics}

Results are expressed as means (SEM) unless otherwise stated. Analyses were performed with ANOVA, the Student's $t$ test, or simple linear regression, as applicable. Differences with $\mathrm{p}<0.05$ were considered significant.

\section{RESULTS}

\section{$C D$ mucosa shows low baseline Isc but equal viability as control tissue}

Ileal mucosa from $\mathrm{CD}(\mathrm{n}=32$ specimens from 10 patients $)$ had lower baseline $\mathrm{I}_{\mathrm{sc}}\left(54(6) \mu \mathrm{A} / \mathrm{cm}^{2}\right)$ compared with control ileum ( 103 (7) $\mu \mathrm{A} / \mathrm{cm}^{2}, \mathrm{n}=23$ specimens from nine patients; $p<0.01$ ). There were however no differences between the patient groups with respect to the rise in $\mathrm{I}_{\mathrm{sc}}$ following transmural electrical stimulation, reflecting neurally mediated activation of anion secretion (CD $v$ control: 41 (9) $\left.v 39(7) \mu \mathrm{A} / \mathrm{cm}^{2} ; \mathrm{p}>0.05\right),{ }^{38}$ or in the Isc response to luminal glucose, activating glucose coupled sodium absorption (CD $v$ control: 85 (20) $\left.v 101(27) \mu \mathrm{A} / \mathrm{cm}^{2} ; \mathrm{p}>0.05\right)$. Initial baseline conductance was also similar in the two study groups (CD $v$ control: 24.4 (1.9) $v 27.3$ (1.7) $\left.\mathrm{mS} / \mathrm{cm}^{2} ; \mathrm{p}>0.05\right)$. These
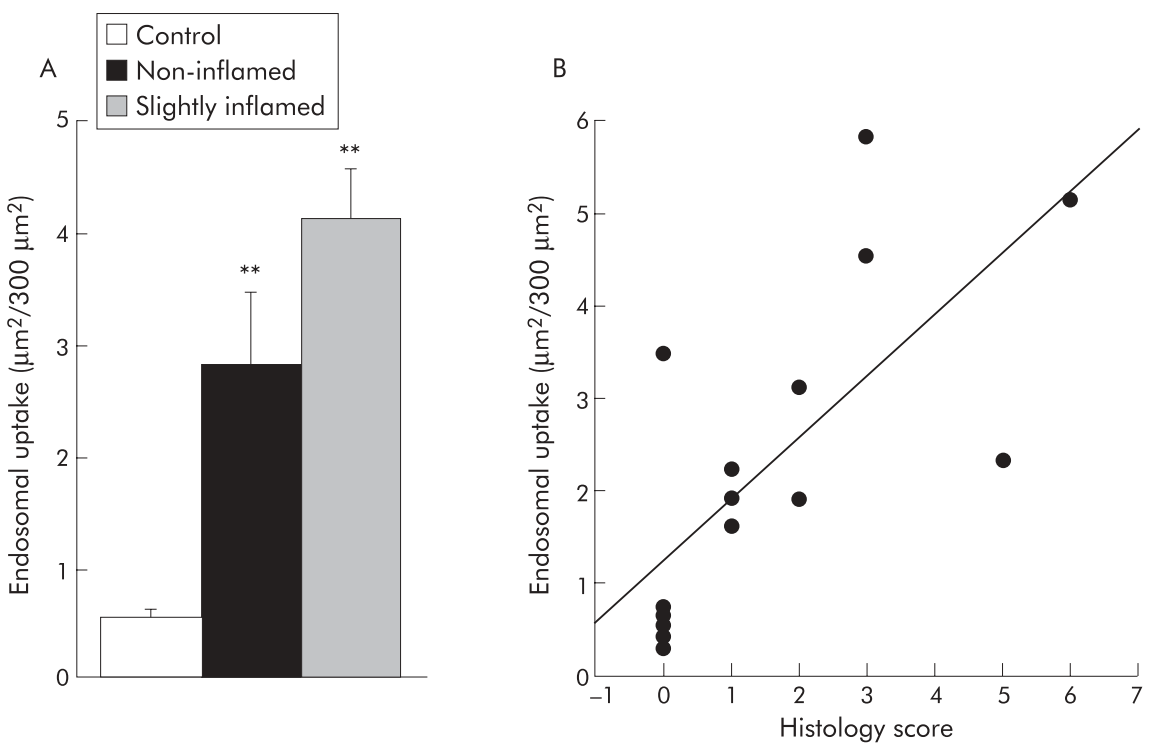

Figure 2 Increased endosomal uptake of horseradish peroxidase (HRP) in Crohn's disease (CD). Quantification of endosomal uptake of HRP in ileal enterocytes of control patients $(n=6)$, non-inflamed $C D(n=6)$, and slightly inflamed mucosa of $C D$ patients $(n=4)$. (A) Data show total area of HRP containing endosomes within enterocytes determined in an area of $300 \mu \mathrm{m}^{2}$ in the apical region of the cells; 12 randomly chosen cells assessed per patient. Values are means (SEM). ${ }^{* *}$ Increased compared with controls, $p<0.01$. (B) Linear regression using the same observations as in (A), with histology score (see table 1) as the independent variable and endosomal uptake as the dependent variable: $r=0.72,+$ value $3.88, p<0.01$. 

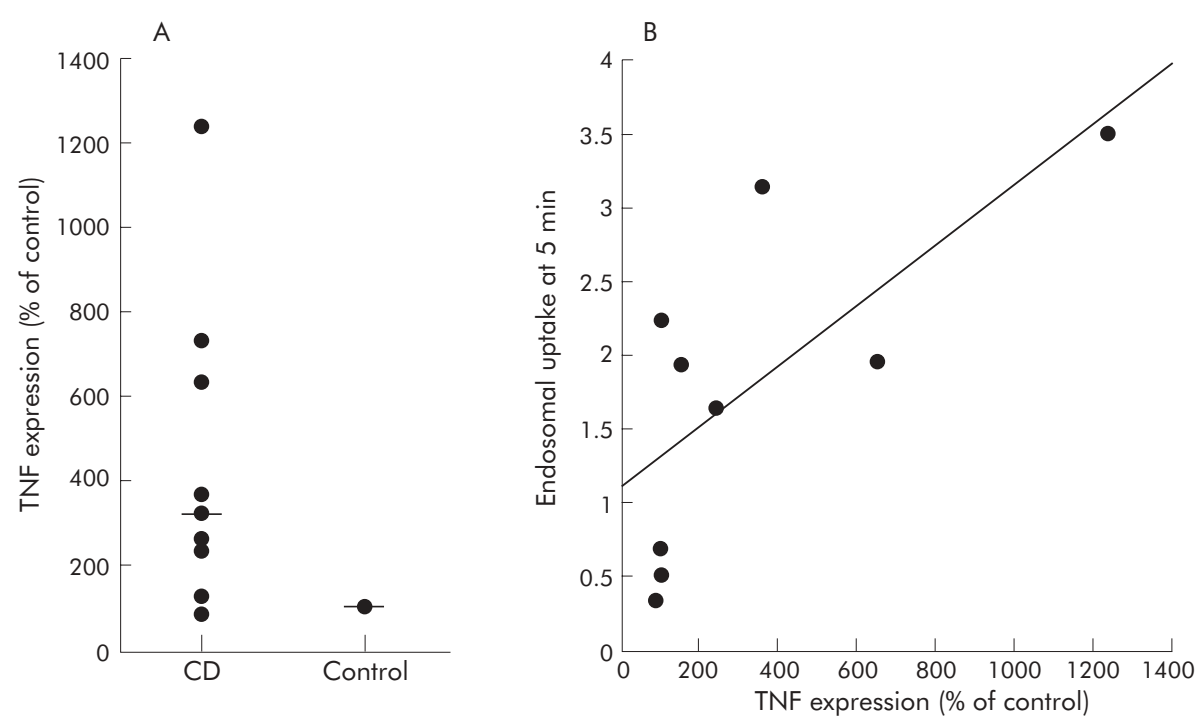

Figure 3 (A) Relative expression of tumour necrosis factor $\alpha$ (TNF- $\alpha$ ) mRNA in ileal tissue of Crohn's disease (CD) and control patients, as determined by real time reverse transcription-polymerase chain reaction. Horizontal line denotes median value. (B) Linear regression using TNF- $\alpha$ expression in controls and non-inflamed $C D$ as the independent variable and endosomal uptake as the dependent variable: $r=0.71, t$ value $2.64, p<0.03$.

findings indicate similar integrity and viability of ileal tissues obtained from patients with CD and colon cancer controls.

\section{Endosomal uptake of HRP is increased in CD}

Endosomal uptake studied after five minutes of luminal exposure showed HRP in small endosomes in the ileum from control patients (fig lA) whereas in CD, larger HRP containing endosomes were found (fig 1B, C). When quantified by image analysis, HRP endosome area was substantially higher in non-inflamed ileum of CD $\left(2.8(0.7) \mu \mathrm{m}^{2} / 300 \mu \mathrm{m}^{2}\right.$ apical cell area, $\mathrm{n}=6$ patients) than in control ileum $(0.6$ (0.06) $\mu \mathrm{m}^{2} / 300 \mu \mathrm{m}^{2}, \mathrm{n}=6$ patients, $\mathrm{p}<0.001$ ) (fig $2 \mathrm{~A}$ ), and was even further increased in the slightly inflamed $C D$ specimens (4.4 (0.4) $\mathrm{mm}^{2} / 300 \mu \mathrm{m}^{2}, \mathrm{n}=4$ patients) (fig $2 \mathrm{~A}$ ). Linear regression showed a significant association between histology score and area of HRP containing endosomes $(\mathrm{p}<0.01$; fig $2 \mathrm{~B})$. Endosomal area was increased to a similar extent after 20 minutes of luminal exposure to HRP (control ileum ( $\mathrm{n}=3$ patients) 0.7 (0.2); CD ileum ( $\mathrm{n}=5$ patients) 2.2 (0.5) $\left.\mu \mathrm{m}^{2} / 300 \mu \mathrm{m}^{2} ; \mathrm{p}<0.05\right)$. No HRP was seen in paracellular spaces.

\section{TNF- $\alpha$ mRNA is increased in CD mucosa and is associated with endosomal uptake}

As TNF- $\alpha$ is an important proinflammatory cytokine in CD and a regulator of mucosal barrier function, we assessed tissue levels of TNF- $\alpha$ by real time RT-PCR. TNF- $\alpha$ mRNA levels in ileal tissue of CD patients were increased to $323 \%$ (207-658\%) (median, interquartile range) of control ileum $(p<0.001$; fig $3 \mathrm{~A})$. In the subgroup of patients with noninflamed mucosa (histology score $0-2$ ), endosomal uptake of HRP at five minutes increased with tissue expression of mRNA for TNF- $\alpha(\mathrm{p}=0.03$; fig $3 \mathrm{~B})$.

\section{TNF- $\alpha$ increases HRP flux and endosomal uptake in T84 cell lines}

To elucidate whether the association between mucosal TNF- $\alpha$ and endosomal uptake is of mechanistic importance, the effects of low concentrations of TNF- $\alpha(0.25-10.0 \mathrm{ng} / \mathrm{ml})$ were studied in polarised T84 cells $(\mathrm{n}=9$ filters in each group, three separate experiments). TNF- $\alpha$ caused a dose dependent increase in the area of HRP containing endosomes seen by transmission electron microscopy (fig 4A).
Moreover, HRP flux over two hours increased dose dependently (TNF- $\alpha 1.0 \mathrm{ng} / \mathrm{ml}: 211$ (50)\%; TNF- $\alpha 10.0 \mathrm{ng} / \mathrm{ml}: 304$ $(20) \%$ of control, $\mathrm{p}<0.05)$. On the other hand, TER at 48 hours was unaffected by TNF- $\alpha 0.25-1.0 \mathrm{ng} / \mathrm{ml}$, and TNF$\alpha 10.0 \mathrm{ng} / \mathrm{ml}$ caused only a moderate decrease in TER (fig 4B).

\section{DISCUSSION}

The results of the present study suggest a TNF- $\alpha$-dependent increase in endosomal uptake of protein antigens into enterocytes of histologically non-involved ileal mucosa of CD patients. Moreover, in the human colonic cell line, T84, low doses of TNF- $\alpha$ affected endosomal uptake of proteins rather than paracellular permeability. This may imply that enhanced endocytosis precedes the previously recognised increase in paracellular permeability in CD but is none the less secondary to immune activation. Our findings explain previous studies of increased permeability to protein antigens in ileal $\mathrm{CD}^{18}{ }^{19}{ }^{39}$ and also highlight the importance of studying the interaction between the mucosal immune system and epithelial function in IBD pathogenesis.

The pivotal role of TNF- $\alpha$ in CD pathogenesis has become apparent in recent years with the sometimes dramatic effects of anti-TNF- $\alpha$ treatment. ${ }^{40-42}$ TNF- $\alpha$ is produced in excessive amounts by macrophages and mast cells in CD mucosa, ${ }^{43-45}$ and a role for TNF- $\alpha$ released from immune cells has been implicated in the regulation of epithelial barrier function in $\mathrm{CD},{ }^{26}$ as well in other settings of intestinal inflammation. ${ }^{27}{ }^{28}$ Moreover, the recent report of Suenaert and colleagues ${ }^{12}$ suggested TNF- $\alpha$ in the regulation of in vivo intestinal permeability in patients with CD. In the present study, we found a significant association between TNF- $\alpha$ mRNA levels and increasing endocytosis of HRP into enterocytes of noninflamed ileal mucosa. In addition, experiments using T84 cells, with TNF- $\alpha$ concentrations in physiological doses (that is, in the lower limits of what has previously been used in cell lines and of the same order of magnitude as spontaneous secretion from human intestinal tissue ${ }^{46}$ ) supported TNF- $\alpha$ as a potential regulator of endosomal uptake of antigens in enterocytes. These novel findings further emphasise the role of TNF- $\alpha$ in the signalling pathways between antigens, epithelial cells, and immune cells in the modulation of gut physiological and pathophysiological reactions in inflammatory bowel disease. 

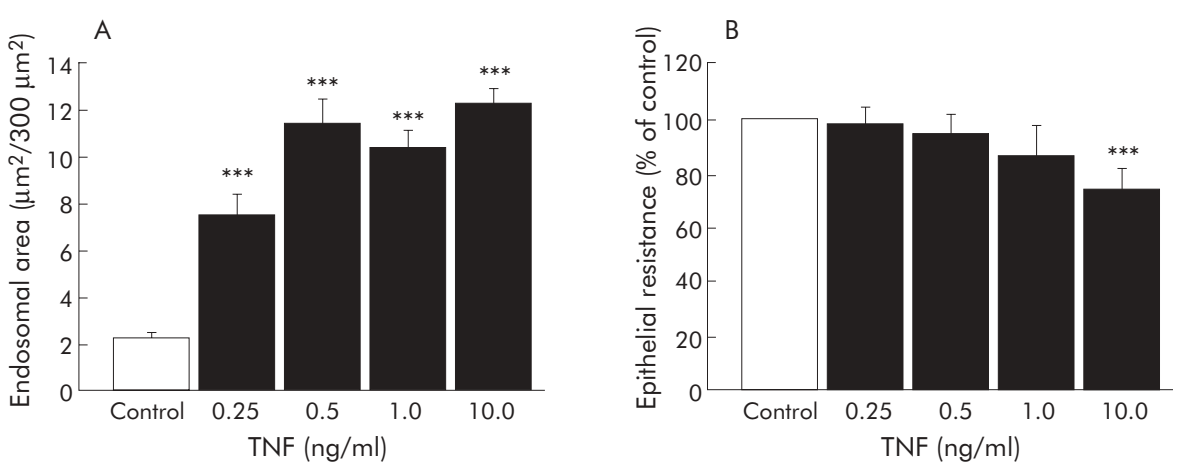

Figure 4 Dose-response effects of tumour necrosis factor $\alpha$ (TNF- $\alpha$ ) in T84 cell lines. (A) Area of horseradish peroxidase (HRP) containing endosomes in epithelial cells. Cells were grown on filter supports with TNF- $\alpha(0.25-10.0 \mathrm{ng} / \mathrm{ml})$ for 48 hours and exposed to HRP in the luminal compartment for two hours. Data show total area of HRP containing endosomes within enterocytes determined in an area of $300 \mu \mathrm{m}^{2}$ in the apical region of the cells; 12 randomly chosen cells assessed per group per experiment. (B) Transepithelial electrical resistance in T84 cells grown with TNF- $\alpha(0.25-10.0 \mathrm{ng} / \mathrm{ml})$ for 48 hours. Data are from three separate experiments with 3-4 filters studied in each group on each occasion; analysis done with $n=3$, ANOVA with Fisher's post hoc test. ${ }^{* * *} \mathrm{p}<0.001$ compared with control experiments.

We previously showed increased permeability to ovalbumin in the non-involved ileum of patients with $\mathrm{CD}$, and indirect evidence suggested transcytosis of proteins. ${ }^{18}$ To test this hypothesis, the present study focused on detection of endosomal uptake into ileal enterocytes. We were able to verify increased uptake of antigenic proteins into the epithelial cells of non-involved ileum, a previously unproven defect in epithelial barrier function in CD. A possible interpretation is that enhanced endosomal uptake, once triggered by TNF- $\alpha$ signalling from the lamina propria, could result in increased transcytosis of intact proteins or increased presentation of antigen fragments by the MHC complexes of enterocytes to immunocytes of the lamina propria. ${ }^{47}$ These events could then serve as accelerators of the process in the early stages of mucosal inflammation. The additional increase in endocytosis in inflamed mucosa, which was unrelated to mRNA levels of TNF- $\alpha$, implies that in more overt inflammation other inflammatory mediators are important in regulating endocytotic uptake into enterocytes (for example, neutrophil released oxygen and nitrogen radicals). ${ }^{48}$ The immune response to an endocytosed antigen is regulated by targeting to late endosomes containing lysosome associated membrane protein 1 and MHC class II. ${ }^{49}$ Further studies are needed to determine regulation of the intracellular trafficking of endosomal proteins within enterocytes of ileal CD.

An alternative explanation for our findings could be that TNF- $\alpha$ induced an increase in apoptosis of epithelial cells, ${ }^{50}$ with increased epithelial turnover and more immature cells (with more active endocytosis) reaching the absorptive part of the villi. This could result in increased paracellular leakage at apoptotic foci, as has been described in ulcerative colitis. ${ }^{20}$ These leaking foci would not be detected with the conventional resistance measurements used in the present study. ${ }^{51}$ Further studies are needed to address this point.

In recent years it has become evident that the epithelium is in constant interplay with luminal bacteria and dietary antigens, as well as with the mucosal immune system. ${ }^{52}$ One important contributing factor is the genetic susceptibility of $\mathrm{CD}$, as recently highlighted by the discovery of mutations in the NOD2/CARD15 gene in $30 \%$ of CD patients..$^{53}{ }^{54}$ This could lead to reduced protection against luminal bacteria ${ }^{55}$ and a hyperreactive innate immune system, giving an elevated background level of TNF- $\alpha$ with epithelial barrier dysfunction as a consequence. ${ }^{26}$

The control group of colon cancer patients employed in this study was substantially older than the CD patients but intestinal permeability does not seem to be affected by aging. ${ }^{46}$ An increase in intestinal permeability has been found in advanced malignancy or related to chemotherapy. ${ }^{4}$ However, the cancer patients included in the present study had no signs of generalised disease, did not receive chemotherapy, and were in a good nutritional condition. Most CD patients were receiving treatment with corticosteroids and mesalazine. In experimental intestinal inflammation these drugs seem to tighten the barrier. ${ }^{57}{ }^{58}$ In the present study, there were no differences in HRP uptake between patients with and without corticosteroid treatment. Therefore, medication is not likely to explain the differences in endosomal antigen uptake observed between the patient groups.

Samples taken close to the specimens studied in the Ussing chambers, as well as the resection margins from all patients, were scrutinised by histopathology. The "non-inflamed" CD group had a normal macroscopic and light microscopy appearance when reviewed for clinical purposes but had scores of $0-2$ (and increased TNF- $\alpha$ expression) when scrutinised in more detail. This indicates inflammatory load in clinically non-involved areas, and supports the concept of barrier dysfunction being secondary to low grade inflammation. Mucosal specimens from CD patients also demonstrated a low baseline Isc, probably reflecting reduced net ion pump activity. It was recently shown that TNF- $\alpha$ reduces epithelial cell secretory function by inhibiting $\mathrm{Na}+\mathrm{K}+$-ATPase activity by a specific cytokine effect not implying reduced viability. ${ }^{59}$ Our findings regarding electrophysiology should however be viewed with caution as it was previously shown that conventional methods for measurements of Isc and TER in inflamed human tissue are handicapped by an increase in subepithelial resistance which overestimates epithelial resistance and underestimates Isc. ${ }^{51}$ Conventional methods are nevertheless adequate in reflecting changes in Isc, and in the present study, we found similar epithelial secretory function in the patient groups, as assessed by measuring Isc changes to transmural electric nerve stimulation, and absorptive function, studied by Isc response to glucose activation of $\mathrm{Na}+$ /glucose co-transporters, in mucosa from CD and control patients.

In summary, we have shown for the first time that endosomal uptake of protein antigens is increased in histologically non-involved ileum of CD, and may be regulated by TNF- $\alpha$. These novel findings lend further support to the importance of the transcellular route of antigen uptake in the barrier dysfunction of CD, and underline the importance of immune-epithelial interaction in the development of mucosal inflammation. In addition, 
these findings may give additional explanations for the positive effects of anti-TNF- $\alpha$ treatment in patients suffering from CD.

\section{ACKNOWLEDGEMENTS}

Funded by a Group Grant from the Crohn's and Colitis Foundation of Canada (MP, DM, PS, JS), the Broad Medical Research Program of the Eli and Edythe L Broad Foundation (JS), and the Swedish Research Council (JS). At the time of the human tissue experiments, JS was a postdoctoral fellow sponsored by the Canadian Institutes of Health Research. PS is the recipient of a Canadian Research Chair in Gastrointestinal Disease.

\section{Authors' affiliations}

J D Söderholm, Department of Surgery and Clinical Research Centre, University Hospital, Linköping, Sweden, and Intestinal Disease Research Programme, McMaster University, Hamilton, Canada

C Streutker, Intestinal Disease Research Programme, McMaster University, Hamilton, Canada, and Department of Laboratory Medicine and Pathology, St. Michael's Hospital and the University of Toronto,

Toronto, Ontario, Canada

P-C Yang, C Paterson, P K Singh, D M McKay, K Croitoru, M H Perdue, Intestinal Disease Research Programme, McMaster University, Hamilton, Canada

P M Sherman, Research Institute, Hospital for Sick Children, University of Toronto, Toronto, Ontario, Canada

\section{REFERENCES}

1 Yamada T, Sartor RB, Marshall S, et al. Mucosal injury and inflammation in a model of chronic granulomatous colitis in rats. Gastroenterology 1993; 104:759-71.

2 Hermiston ML, Gordon Jl. Inflammatory bowel disease and adenomas in mice expressing a dominant negative N-cadherin. Science 1995;270:1203-7.

3 Mashimo H, Wu DC, Podolsky DK, et al. Impaired defense of intestinal mucosa in mice lacking intestinal trefoil factor. Science 1996;274:262-5.

4 Bjarnason I, MacPherson A, Hollander D. Intestinal permeability: an overview. Gastroenterology 1995; 108:1566-81.

5 Meddings JB. Review article: Intestinal permeability in Crohn's disease. Aliment Pharmacol Ther 1997;11(suppl3):47-53.

6 Hollander D, Vadheim CM, Brettholz E, et al. Increased intestinal permeability in patients with Crohn's disease and their relatives. A possible etiologic factor. Ann Intern Med 1986; 105:883-5.

7 May GR, Sutherland LR, Meddings JB. Is small intestinal permeability really increased in relatives of patients with Crohn's disease? Gastroenterology 1993; 104: 1627-32.

8 Hilsden RJ, Meddings JB, Sutherland LR. Intestinal permeability changes in response to acetylsalicylic acid in relatives of patients with Crohn's disease. Gastroenterology 1996;110:1395-403.

9 Peeters M, Geypens B, Claus D, et al. Clustering of increased small intestinal permeability in families with Crohn's disease. Gastroenterology 1997; 113:802-7.

10 Soderholm JD, Olaison G, Lindberg E, et al. Different intestinal permeability patterns in relatives and spouses of patients with Crohn's disease: an inherited defect in mucosal defence? Gut 1999;44:96-100.

11 Irvine EJ, Marshall JK. Increased intestinal permeability precedes the onset of Crohn's disease in a subject with familial risk. Gastroenterology 2000;119:1740-4.

12 Suenaert $\mathbf{P}$, Bulteel V, Lemmens L, et al. Anti-tumor necrosis factor treatment restores the gut barrier in Crohn's disease. Am J Gastroenterol 2002;97:2000-4.

13 Yacyshyn BR, Meddings JB. CD45RO expression on circulating CD19+ B cells in Crohn's disease correlates with intestinal permeability. Gastroenterology 1995; 108:132-7.

14 Thjodleifsson B, Sigthorsson G, Cariglia N, et al. Subclinical intestinal inflammation: an inherited abnormality in Crohn's disease relatives? Gastroenterology 2003;124:1728-37.

15 Soderholm JD, Yang PC, Ceponis P, et al. Chronic psychological stress induces mast cell-dependent bacterial internalization into enterocytes and mucosal inflammation in rat intestine. Gastroenterology 2002; 123:1099-108

16 Berin MC, Kiliaan AJ, Yang PC, et al. The influence of mast cells on pathways of transepithelial antigen transport in rat intestine. J Immunol 1998;161:2561-6.

17 Soderholm JD, Olaison G, Peterson KH, et al. Augmented increase in tight junction permeability by luminal stimuli in the non-inflamed ileum of Crohn's disease. Gut 2002;50:307-13.

18 Soderholm JD, Peterson KH, Olaison G, et al. Epithelial permeability to proteins in the noninflamed ileum of Crohn's disease? Gastroenterology 1999;117:65-72.

19 Schurmann G, Bruwer M, Klotz A, et al. Transepithelial transport processes at the intestinal mucosa in inflammatory bowel disease. Int J Colorectal Dis $1999 ; 14: 41-6$.
20 Gitter AH, Wullstein F, Fromm M, et al. Epithelial barrier defects in ulcerative colitis: characterization and quantification by electrophysiological imaging. Gastroenterology 2001;121:1320-8

21 Anderson JM. Molecular structure of tight junctions and their role in epithelial transport. News Physiol Sci 2001;16:126-30.

22 Berkes J, Viswanathan VK, Savkovic SD, et al. Intestinal epithelial responses to enteric pathogens: effects on the tight junction barrier, ion transport, and inflammation. Gut 2003;52:439-51.

23 Fasano A. Regulation of intercellular tight junctions by zonula occludens toxin and its eukaryotic analogue zonulin. Ann N Y Acad Sci 2000;915:214-22.

24 Karczewski J, Groot J. Molecular physiology and pathophysiology of tight junctions III. Tight junction regulation by intracellular messengers: differences in response within and between epithelia, Am J Physiol 2000;279:G660-5.

25 Nusrat A, Turner JR, Madara JL. Molecular physiology and pathophysiology of tight junctions. IV. Regulation of tight junctions by extracellular stimuli: nutrients, cytokines, and immune cells, Am J Physiol 2000;279:G851-7.

26 Zareie M, Singh PK, Irvine EJ, et al. Monocyte/macrophage activation by normal bacteria and bacterial products: implications for altered epithelial function in Crohn's disease. Am J Pathol 2001;158:1101-9.

27 Schmitz H, Rokos K, Florian P, et al. Supernatants of HIV-infected immune cells affect the barrier function of human HT-29/B6 intestinal epithelial cells. AIDS 2002; 16:983-91.

28 Heyman M, Darmon N, Dupont C, et al. Mononuclear cells from infants allergic to cow's milk secrete tumor necrosis factor alpha, altering intestinal function. Gastroenterology 1994;106:1514-23.

29 McKay DM, Singh PK. Superantigen activation of immune cells evokes epithelial (T84) transport and barrier abnormalities via IFN-gamma and TNF alpha: inhibition of increased permeability, but not diminished secretory responses by TGF-beta2. J Immunol 1997; 159:2382-90.

30 Soderholm JD, Hedman L, Artursson P, et al. Integrity and metabolism of human ileal mucosa in vitro in the Ussing chamber. Acta Physiol Scand 1998; 162:47-56

31 Graham RC Jr, Karnovsky MJ. Glomerular permeability. Ultrastructural cytochemical studies using peroxidases as protein tracers. J Exp Med 1966;124:1123-34.

32 Kiliaan AJ, Saunders PR, Biilsma PB, et al. Stress stimulates transepithelial macromolecular uptake in rat jejunum. Am J Physiol 1998;275:G1037-44.

33 Berin MC, Kiliaan AJ, Yang PC, et al. Rapid transepithelial antigen transport in rat jejunum: impact of sensitization and the hypersensitivity reaction. Gastroenterology 1997; 113:856-64.

34 Santos J, Yang PC, Soderholm JD, et al. Role of mast cells in chronic stressinduced colonic epithelial barrier dysfunction in the rat. Gut $2001 ; 48: 630-6$

35 Schmitz H, Fromm M, Bentzel CJ, et al. Tumor necrosis factor-alpha (TNFalpha) regulates the epithelial barrier in the human intestinal cell line HT29/B6. J Cell Sci 1999;112:137-46.

36 Yoo J, Nichols A, Song JC, et al. Bryostatin-1 attenuates TNF-induced epithelial barrier dysfunction: role of novel PKC isozymes. Am J Physiol 2003;284:G703-12.

37 Zareie M, McKay DM, Kovarik GG, et al. Monocyte/macrophages evoke epithelial dysfunction: indirect role of tumor necrosis factor-alpha. Am J Physiol 1998;275:C932-9.

38 Crowe SE, Luthra GK, Perdue MH. Mast cell mediated ion transport in intestine from patients with and without inflammatory bowel disease. Gut 1997;41:785-92

39 Malin $M$, Isolauri E, Pikkarainen $P$, et al. Enhanced absorption of macromolecules. A secondary factor in Crohn's disease. Dig Dis Sci 1996:41:1423-8.

40 Baert FJ, D'Haens GR, Peeters M, et al. Tumor necrosis factor alpha antibody (infliximab) therapy profoundly down-regulates the inflammation in Crohn's ileocolitis. Gastroenterology 1999;116:22-8.

41 D'haens G, Van Deventer S, Van Hogezand R, et al. Endoscopic and histological healing with infliximab anti-tumor necrosis factor antibodies in Crohn's disease: A European multicenter trial. Gastroenterology 1999; 116:1029-34

42 Targan SR, Hanauer SB, van Deventer SJ, et al. A short-term study of chimeric monoclonal antibody cA2 to tumor necrosis factor alpha for Crohn's disease. Crohn's Disease cA2 Study Group. N Engl J Med 1997;337:1029-35.

43 Gelbmann CM, Mestermann S, Gross V, et al. Strictures in Crohn's disease are characterised by an accumulation of mast cells colocalised with laminin but not with fibronectin or vitronectin. Gut 1999:45:210-7.

44 Lilja I, Gustafson-Svard C, Franzen L, et al. Tumor necrosis factor-alpha in ileal mast cells in patients with Crohn's disease. Digestion 2000;61:68-76.

45 Bischoff SC, Lorentz A, Schwengberg S, et al. Mast cells are an important cellular source of tumour necrosis factor alpha in human intestinal tissue. Gut 1999;44:643-52.

46 Ishiguro Y. Mucosal proinflammatory cytokine production correlates with endoscopic activity of ulcerative colitis. J Gastroenterol 1999;34:66-74.

47 Mayer L. Current concepts in mucosal immunity. I. Antigen presentation in the intestine: new rules and regulations, Am J Physiol 1998;274:G7-9.

48 Jijon HB, Churchill T, Malfair D, et al. Inhibition of poly(ADP-ribose) polymerase attenuates inflammation in a model of chronic colitis. Am J Physiol 2000;279:G641-51.

49 Zimmer KP, Buning J, Weber P, et al. Modulation of antigen trafficking to $\mathrm{MHC}$ class II-positive late endosomes of enterocytes. Gastroenterology 2000;1 18:128-37.

50 Bojarski C, Gitter AH, Bendfeldt K, et al. Permeability of human HT-29/B6 colonic epithelium as a function of apoptosis. J Physiol 2001;535:541-52.

51 Schmitz H, Barmeyer C, Fromm M, et al. Altered tight junction structure contributes to the impaired epithelial barrier function in ulcerative colitis. Gastroenterology 1999;116:301-9. 
52 Berin MC, McKay DM, Perdue MH. Immune-epithelial interactions in host defense. Am J Trop Med Hyg 1999;60:16-25.

53 Hugot JP, Chamaillard M, Zouali $\mathrm{H}$, et al. Association of NOD2 leucine-rich repeat variants with susceptibility to Crohn's disease. Nature 2001:411:599-603.

54 Ogura $\mathrm{Y}$, Bonen DK, Inohara N, et al. A frameshift mutation in NOD2 associated with susceptibility to Crohn's disease. Nature 2001;411:603-6.

55 Hisamatsu T, Suzuki M, Reinecker HC, et al. CARD15/NOD2 functions as an antibacterial factor in human intestinal epithelial cells. Gastroenterology 2003;124:993-1000.
56 Salzman JR, Kowdley KV, Perrone G, et al. Changes in small-intestine permeability with aging. J Am Geriatr Soc 1995;43:160-4

57 Di Paolo MC, Merrett MN, Crotty B, et al. 5-Aminosalicylic acid inhibits the impaired epithelial barrier function induced by gamma interferon. Gut 1996;38:115-19.

58 McKay DM, Brattsand R, Wieslander E, et al. Budesonide inhibits T cellinitiated epithelial pathophysiology in an in vitro model of inflammation. J Pharmacol Exp Ther 1996;277:403-10.

59 Musch MW, Clarke LL, Mamah D, et al. T cell activation causes diarrhea by increasing intestinal permeability and inhibiting epithelial $\mathrm{Na}+/ \mathrm{K}+-\mathrm{ATPase}$. J Clin Invest 2002;110:1739-47.

\section{EDITOR'S QUIZ: GI SNAPSHOTS}

\section{An unusual case of colitis}

\section{Clinical presentation}

A 76 year old woman presented with a two month history of increasingly frequent bowel motions and weight loss. She had a history of diverticular disease diagnosed on barium enema 10 years previously. Physical examination was unremarkable. Blood tests showed normocytic anaemia and neutrophilia. Flexible sigmoidoscopy showed severe inflammation with histological changes of mild active chronic colitis, with crypt abscesses. Her diarrhoea responded well to intravenous steroids and oral mesalazine.

She was readmitted two months later with acute exacerbation confirmed on sigmoidoscopy. Computed tomography showed sigmoid diverticular disease and no lymphadenopathy. She was managed with antibiotics, an increased dose of steroids, and mesalazine enemas. Colonoscopy confirmed chronic pancolitis with a normal terminal ileum and some rectal sparing. Azathioprine was commenced but stopped after four weeks because of severe parotitis. She improved gradually and was discharged after six weeks but was readmitted seven months later with colonic perforation requiring emergency subtotal colectomy.

\section{Question}

Figures 1 and 2 show the histology from the resected specimen. Is this the typical appearance of ulcerative colitis or is there another possible diagnosis?

See page 1849 for answer

This case is submitted by:

S Payne, M Phillips, D Reffitt, H Fidler, D Birch, D Joshi, J Norton, J O'Donohue University Hospital Lewisham, London, UK

Correspondence to: $\mathrm{Dr} J$ O'Donohue, University Hospital Lewisham, London SE13 6LH, UK; john.o'donohue@uhl.nhs.uk

doi: $10.1136 /$ gut.2004.040451
Robin Spiller, Editor

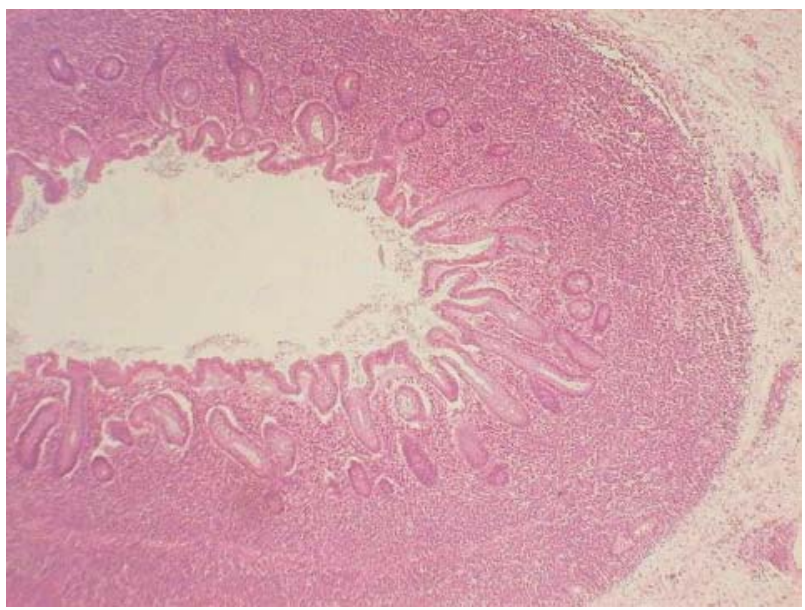

Figure 1 Haematoxilin and eosin stain of the colon showing diffuse infiltration of the lamina propria by a monomorphic population of lymphoid cells.

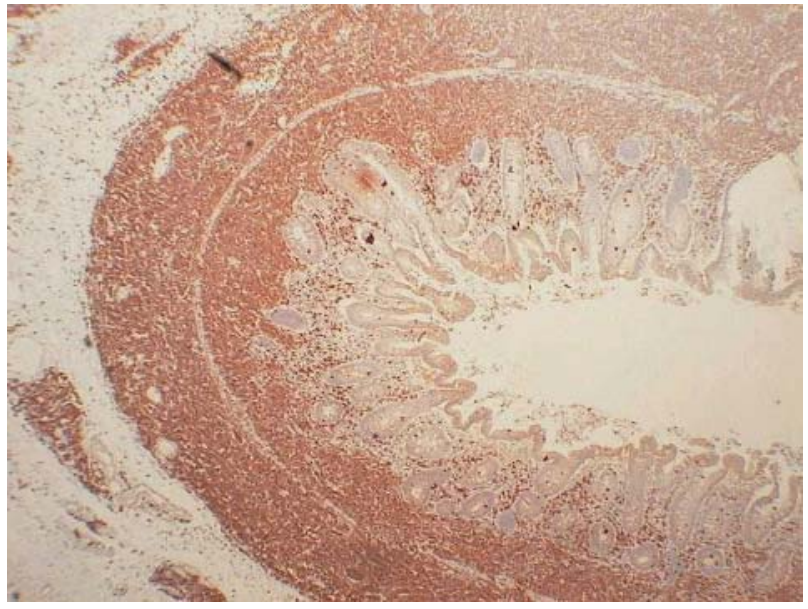

Figure 2 Staining of the same sample for CD3 expression, confirming T cell phenotype. 